\title{
Astro3D: um simulador do movimento de corpos celestes
}

\author{
Astro3D: the simulator of motion of the celestial bodies
}

\author{
Artur Justiniano*1, Paulo Alexandre Bressan ${ }^{2}$, Eliza Maria Silva ${ }^{3}$, Leandro Donizete Moraes ${ }^{1}$, \\ Rafael Botelho ${ }^{4}$ \\ ${ }^{1}$ Instituto de Ciências Exatas, Universidade Federal de Alfenas, Rua Gabriel Monteiro da Silva, 700, Centro, 37130000, \\ Alfenas, MG, Brazil \\ ${ }^{2}$ Departamento de Ciência da Computação, Universidade Federal de Alfenas, Alfenas, MG, Brazil \\ ${ }^{3}$ Universidade Federal de Juiz de Fora, Juiz de Fora, MG, Brazil \\ ${ }^{4}$ Instituto Nacional de Pesquisas Espaciais, São José dos Campos, SP, Brazil
}

Recebido em 13 de Abril, 2017. Revisado em 10 de Maio, 2017. Aceito em 13 de Maio, 2017

\begin{abstract}
Nesse trabalho nós apresentamos o software Astro3D. Trata-se de um simulador do movimento dos corpos celestes em dois referenciais, o topocêntrico e o heliocêntrico. Com o Astro3D é possível observar de forma simultânea o movimento real e o movimento aparente do Sol, da Lua e dos planetas do sistema solar. Trata-se de um recurso computacional, desenvolvido para o ensino de física e de astronomia, que contribui na visualização de movimentos com escala de tempo muito longa, na compreensão de conceitos abstratos e na construção de modelos mentais que dificilmente podem ser compreendidos sem esse tipo de ferramenta tecnológica.
\end{abstract}

Palavras-chave: Astronomia, Simulador, Mecânica Celeste.

In this work we present the software Astro3D. It is a simulator of motion of the celestial bodies in two references, the topocentric and the heliocentric. With Astro3D you can simultaneously observe the real movement and apparent movement of the Sun, the Moon and the planets of the solar system. It is a computational resource, developed for the teaching of physics and astronomy, which contributes to the visualization of motions with a very long time scale, in the understanding of abstract concepts and in the construction of mental models that can hardly be understood without this type of technological tool.

Keywords: Simulator, Astronomy, Celestial Mechanics.

\section{Introdução}

O movimento dos corpos celestes sempre atraiu a atenção dos seres humanos, seja por motivos científicos, econômicos ou sociais, estudá-los é uma das atividades humanas mais antigas.

O modelo geocêntrico de Ptolomeu e o modelo heliocêntrico de Copérnico, que no século XVI competiam entre si como a explicação correta sobre o modelo geométrico do universo [1], são exemplos de uma construção humana desenvolvida a partir da observação na esfera celeste do movimento periódico do Sol, da Lua e dos planetas.

O estudo desses movimentos levou ao desenvolvimento das leis de Kepler e da lei da gravitação universal [2] que derrubaram a visão aristotélica-ptolomaica do universo [1]. Essa revolução científica, junto com o desenvolvimento dos métodos matemáticos aplicados à física, a partir do século XVIII, lançaram as bases da mecânica celeste.

A partir da segunda metade do século XX houve um avanço nas pesquisas nessa área, impulsionada pelo de-

*Endereço de correspondência: arturjustiniano@gmail.com senvolvimento de computadores mais velozes capazes de simular o movimento dos corpos celestes com bastante precisão. Além disso, passaram a ser desenvolvidos softwares como Celestia, Stellarium e o Cartes do Ciel, só para citar alguns exemplos, e mais recentemente aplicativos para dispositivos móveis como o Skeye e o SkyMap, que simulam o céu para qualquer local do planeta, para uma data no futuro ou no passado. Planetários e cartas celestes passaram a ser artigos para o lazer, o ensino [3, 4 e 5] ou a pesquisa para qualquer pessoa interessada e que possua um tablet, smartphone ou um computador.

Na educação formal, onde o estudo dos movimentos dos corpos celeste faz parte do currículo da disciplina de física [6], a utilização desses recursos computacionais é uma estratégia pedagógica que pode contribuir na visualização de movimentos com escala de tempo muito longa, na compreensão de conceitos abstratos, na visualização dos sistemas de coordenadas e na construção de modelos mentais que dificilmente podem ser compreendidos sem esse tipo de ferramenta tecnológica [7].

Pensando nisso, nesse trabalho nós vamos apresentar o simulador de movimento dos astros denominado Astro3D. Trata-se de um software que foi desenvolvido para ser utilizado no ensino de física e astronomia e que faz 
uma simulação tridimensional do movimento aparente do Sol, da Lua, dos planetas e de algumas constelações para um observador na superfície da Terra (referencial topocêntrico) e também o movimento dos planetas ao redor do Sol (referencial heliocêntrico).

$\mathrm{O}$ artigo está dividido em três partes. Na primeira apresentamos os conceitos que foram utilizados no desenvolvimento do Astro3D. São eles, os sistemas de coordenadas celestes e as leis de Kepler. Na segunda parte apresentamos uma descrição do Astro3D e das suas funcionalidades. E na terceira, mostramos alguns exemplos de movimentos e comportamentos dos astros na esfera celeste que podem ser simulados com o software.

\section{Suporte Teórico}

Vamos descrever os três sistemas de coordenadas celestes que são utilizados para identificar a posição de um objeto no céu no referencial topocêntrico. O leitor interessado no assunto pode encontrar uma discussão mais detalhada nas referências [8], [9] e [10].

O primeiro é o sistema horizontal (Fig. 1a) que tem como plano fundamental o plano que contém o horizonte do observador e duas coordenadas: o azimute (Az) e a altura (h). O azimute é o ângulo, medido sobre o horizonte, com origem no norte, que cresce na direção leste e tem sua extremidade no meridiano do astro, varia de 0 a 360 graus. A altura é o ângulo, medido sobre o meridiano do astro, com origem no horizonte e extremidade no astro, varia de 0 a 90 graus para os astros que estão acima do horizonte. No sistema horizontal, Az e h dependem da localização do observador e mudam a todo momento devido à rotação da Terra.

No sistema equatorial (Fig. 1b) a posição do observador não altera as coordenadas do astro. Nesse sistema o plano fundamental é o plano do equador celeste, o ponto de referência é a posição do Sol (ponto $\gamma$ ) no momento que ele cruza o equador celeste vindo do hemisfério sul e as duas coordenadas são a ascensão reta $(\alpha)$ e a declinação $(\delta)$. A ascensão reta é um ângulo, medido sobre o equador celeste, com origem no ponto gama e extremidade no meridiano do astro. E a declinação é o ângulo, medido sobre o meridiano do astro, com origem no equador celeste e extremidade no astro. Geralmente a ascensão reta é medida em horas, de 0 a 24 horas, e a declinação em graus, de 0 a 90 graus do equador para o pólo norte celeste e de 0 a -90 graus, do equador para o pólo sul celeste.

A relação entre o sistema equatorial e o sistema horizontal para um determinado ângulo horário $(\mathrm{H})$ [8] e em uma determinada latitude $(\varphi)$ é dada pelas seguintes equações:

$$
\begin{gathered}
\operatorname{senh}=[\operatorname{sen}(\delta) \operatorname{sen}(\phi)+\cos (\delta) \cos (\phi) \cos (H)], \\
\cos A z=\left[\frac{\operatorname{sen}(\delta)-\operatorname{sen}(\phi) \operatorname{sen}(h)}{\cos (\phi) \cos (h)}\right] .
\end{gathered}
$$

Como as estrelas estão muito distantes da Terra e o seu movimento orbital é imperceptível podemos considerar que suas coordenadas equatoriais não são modificadas devido ao movimento diurno de rotação da Terra, como ocorre com as coordenadas horizontais, necessitando apenas de pequenas correções em uma escala de tempo de anos, devido à precessão do equinócio [8].

Já os astros do sistema solar movem-se muito rapidamente em suas órbitas, e, por isso, diferente das estrelas, suas coordenadas equatoriais mudam diariamente. Neste caso, a posição do astro na esfera celeste é determinada no sistema de coordenadas eclípticas (Fig. 1c) que tem como plano fundamental o plano da órbita da Terra em torno do Sol e duas coordenadas, a longitude eclíptica $(\lambda)$ e a latitude eclíptica $(\beta)$. A longitude eclíptica é um ângulo, medido sobre a eclíptica, com origem no ponto $\gamma$ e extremidade no meridiano do astro, varia de 0 a 360 graus. A latitude eclíptica é um ângulo, com origem no ponto onde o meridiano do astro toca a eclíptica e extremidade no astro, varia de 0 a 90 graus para o pólo celeste norte e de 0 a -90 graus para o pólo celeste sul.

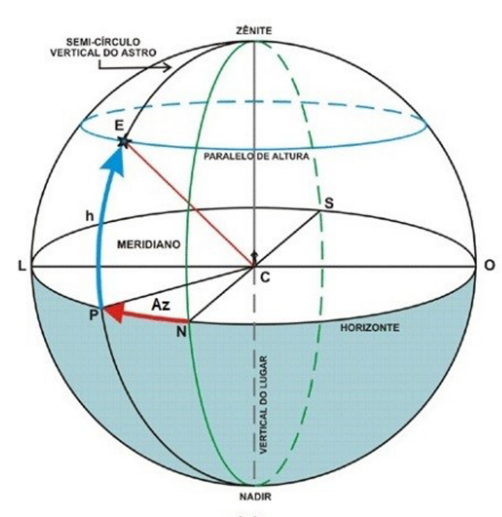

(a)

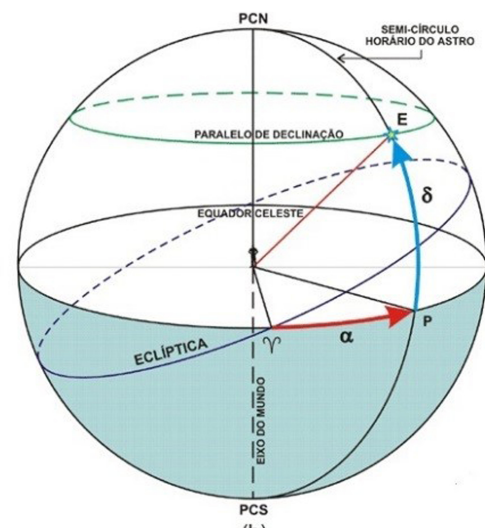

(b)

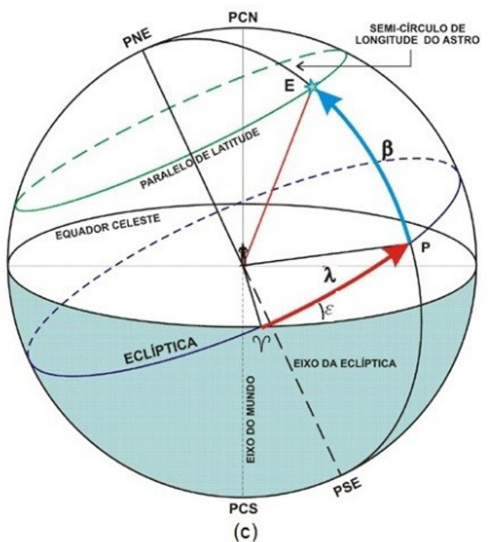

(c)

Figura 1: Sistemas de coordenadas celestes. Em (a) o sistema horizontal de coordenadas, em (b) o sistema equatorial e em (c) o sistema eclíptico. Extraído da referência [9]. 
A relação entre o sistema eclíptico e o sistema equatorial para uma determinada inclinação da eclíptica $(\varepsilon)$ é dada pelas seguintes equações:

$$
\begin{gathered}
\sin \delta=[\operatorname{sen}(\beta) \cos (\varepsilon)+\cos (\beta) \operatorname{sen}(\varepsilon) \operatorname{sen}(\lambda)], \\
\tan \alpha=\left[\frac{\operatorname{sen}(\lambda) \cos (\epsilon)-\tan (\beta) \operatorname{sen}(\varepsilon)}{\cos (\lambda)}\right]
\end{gathered}
$$

Até agora nós tratamos da localização e do movimento dos astros na esfera celeste em um referencial topocêntrico. A partir de agora vamos tratar do movimento em um referencial heliocêntrico. Neste caso vamos utilizar os elementos orbitais do Sol, da Lua, dos Planetas e as leis de Kepler. Uma discussão mais completa sobre esse assunto pode ser encontrada nas referências [10], [11] e [12] .

Os elementos orbitais são utilizados para localizar um objeto dentro do sistema solar. A Figura (2) mostra de forma esquemática o plano da eclíptica, o plano da órbita de um corpo celeste e alguns dos seus principais elementos orbitais. Dentre eles destacamos:

- Inclinação $(i)$ - ângulo formado entre a órbita do planeta e o plano da eclíptica.

- Argumento do periélio $(\omega)$ - ângulo, medido sobre o plano orbital do corpo, entre o periélio $\mathrm{P}$ e o nodo ascendente, contado no sentido do movimento do corpo.

- Anomalia verdadeira $(v)$ - ângulo formado pelo seguimento Sol-planeta medido no eixo maior da elipse, contado a partir do periélio.

- Longitude do nodo ascendente $(\Omega)$ - ângulo entre o ponto $\gamma$ e o nodo ascendente do corpo.

- Longitude do periélio $(\bar{\omega})$ - definida como a soma algébrica entre a longitude do nodo ascendente $(\Omega)$ e o argumento do periélio $(\omega)$. Neste caso $\varpi=\Omega+\omega$

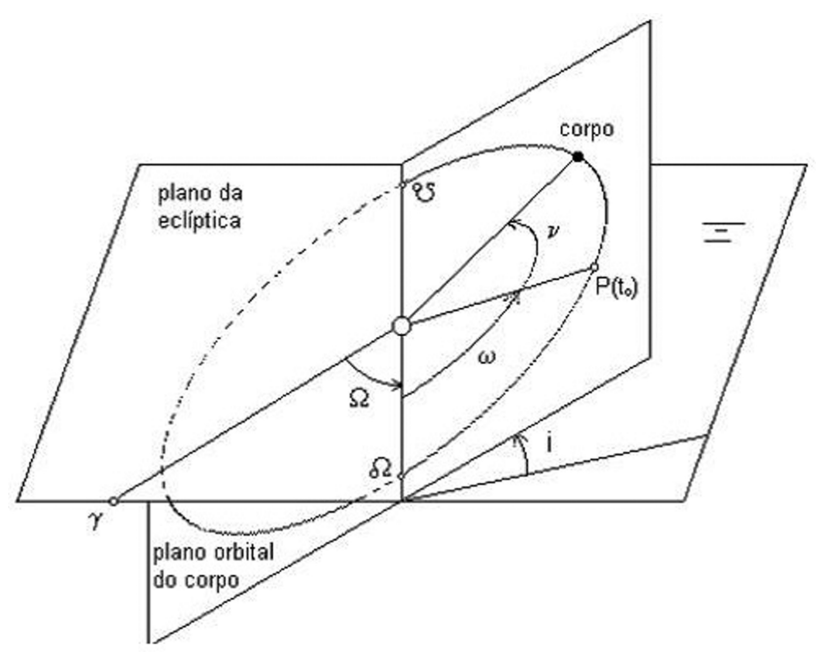

Figura 2: Elementos orbitais de um corpo em órbita do Sol. $\mathrm{P}$ é o periélio do corpo, i é inclinação do plano da órbita, $\omega$ é o argumento do periélio, $\Omega$ é a longitude do nó ascendente e $\nu$ é anomalia verdadeira. Extraído da referência [9].
Além de conhecer os elementos orbitais é necessário também conhecermos as leis de Kepler. Ambas informações são fundamentais para determinarmos as posições dos corpos celestes ao redor do Sol.

A primeira lei diz que as órbitas dos planetas são elipses com o Sol em um dos focos. Em coordenadas polares ela é expressa por:

$$
r(v)=\frac{a\left(1-e^{2}\right)}{1+e \cos (v)},
$$

onde $\mathrm{r}$ é a distância do planeta ao Sol, os parâmetros $(a, e)$ são os elementos orbitais semieixo maior e a excentricidade da órbita e $\nu$ é a anomalia verdadeira.

A Equação (3) mostra o formato da órbita, mas não trata da evolução temporal do planeta ao longo dela. Isto é feito pela segunda lei de Kepler [11], segundo a qual a reta que une o planeta ao Sol percorre áreas (A) iguais em tempos iguais.

$$
\frac{d A}{d t}=\frac{r^{2}}{2} \frac{d v}{d t}=\frac{L}{2 m} .
$$

A segunda lei é consequência da conservação do momento angular orbital do planeta (L). Isso ocorre porque ele está sob a ação de uma força central, a saber, a força de gravitação universal. A demonstração que o lado direito da Equação (4) se conserva com o passar do tempo pode ser consultada nas referências [11 e 12].

Se conhecemos o período da órbita $(T)$, a segunda lei torna possível determinar a posição do planeta em função do tempo. Entretanto, isto não pode ser feito diretamente com expressões analíticas para $r(t)$ e $\nu(t)$ pois não existe uma relação simples entre a posição do planeta e a área percorrida pelo raio vetor. Kepler mostrou que o problema pode ser reduzido ao cálculo da raiz de uma equação transcendental:

$$
M=E-\operatorname{esin}(E)
$$

onde $\mathrm{E}^{1}$ é um ângulo que Kepler chamou de anomalia excêntrica e $\mathrm{M}^{2}$ anomalia média, que pode ser calculada por $M=2 \pi t / T$, onde t é o tempo.

Resolvendo equação de Kepler por um método numérico [13] e encontrando E, a posição do planeta no plano da órbita heliocêntrica pode ser calculada pelas equações:

$$
\begin{gathered}
x=r \cos (v)=a(\cos (E)-e), \\
y=r \sin (v)=a \sqrt{1-e^{2}} \sin (E) .
\end{gathered}
$$

\footnotetext{
1 Anomalia excêntrica (E) é o ângulo entre o centro da órbita e a posição projetada por uma linha perpendicular à linha das apses sobre um círculo que circunscreve a elipse [12].

2 Anomalia Média (M) é um ângulo que relaciona a posição e o tempo para um corpo em movimento em uma órbita Kepleriana. Baseia-se na $2^{\text {a }}$ Lei de Kepler [12].
} 


\section{O Astro3D}

O Astro3D foi programado no ambiente de desenvolvimento Eclipse, na linguagem de programação Java e a biblioteca gráfica OpenGL [14]. Ele possui um banco de dados com as coordenadas equatoriais de 20 constelações, incluindo as zodiacais, e também os elementos orbitais do Sol, da Lua e dos planetas.

A tela principal do Astro3D (Fig.3) mostra o observador na superfície da Terra com os braços abertos. Seu braço direito aponta para o ponto cardeal leste, o esquerdo para o oeste, seu rosto para o norte e suas costas para o sul. Sobre a sua cabeça está a linha meridiana do local da observação. Do lado esquerdo da tela estão as janelas de comando. Nessas janelas o usuário escolhe o local e o momento da observação, o astro (Sol, Lua, planeta ou constelação) e o intervalo de tempo (horas, dias, dias siderais, meses e anos).

Além disso, há a opção de observar, em uma outra tela, o movimento dos planetas numa perspectiva de fora do sistema solar. Nessa tela as órbitas dos planetas ao redor do Sol estão em escala, o que possibilita a observação do movimento de translação desses astros. Dessa forma, o usuário pode, ao mesmo tempo, observar o movimento real e o movimento aparente do planeta.

Para simular o movimento das estrelas no referencial topocêntrico, tela principal, o Astro3D busca no banco de dados as coordenadas equatoriais das estrelas, calcula as suas coordenadas horizontais (Eqs. 1a e 1b) e mostra sua localização na tela principal. No caso dos astros do sistema solar, primeiro são utilizados os elementos orbitais e a data da observação para calcular as coordenadas eclípticas, em seguida essas coordenadas são utilizadas para calcular as coordenadas equatoriais (Eqs. 2a e 2b).
Após isso, com a informação do local e do momento da observação são calculadas as coordenadas horizontais (Eqs. 1a e 1b) do astro e ele é posicionado na tela principal do Astro3D.

Para mostrar a posição dos planetas no referencial heliocêntrico, tela secundária, o Astro3D calcula a anomalia média $(M)$ de cada planeta para o momento da observação, usa esse valor para resolver numericamente a equação de Kepler (Eq. 5) e determina para cada um deles a sua anomalia excêntrica. Em seguida, ele busca no banco de dados os valores da excentricidade $(e)$ e do semieixo maior $(a)$ da órbita para determinar a posição do planeta na sua órbita em torno do Sol (Eqs. 6a e 6b).

\section{Aplicação}

Vamos apresentar três exemplos que mostram como o Astro3D pode ser utilizado no ensino de Astronomia e de Física. O primeiro trata da relação entre o movimento aparente do Sol na esfera celeste e as estações do ano. O segundo é uma simulação do movimento retrógrado de Marte. No terceiro exemplo vamos mostrar como o Astro3D pode ser utilizado para calcular a distância entre um planeta exterior e o Sol pelo método de Copérnico.

\subsection{Movimento do sol na esfera celeste e as estações do ano}

O estudo do movimento aparente do Sol é um assunto tratado na educação básica nas aulas de geografia e de física. Nessa etapa do processo de educação estudar o movimento do Sol contribui na formação científica e cultural do estudante. Já nos cursos de graduação, como por exemplo, engenharia civil, arquitetura e nos cursos

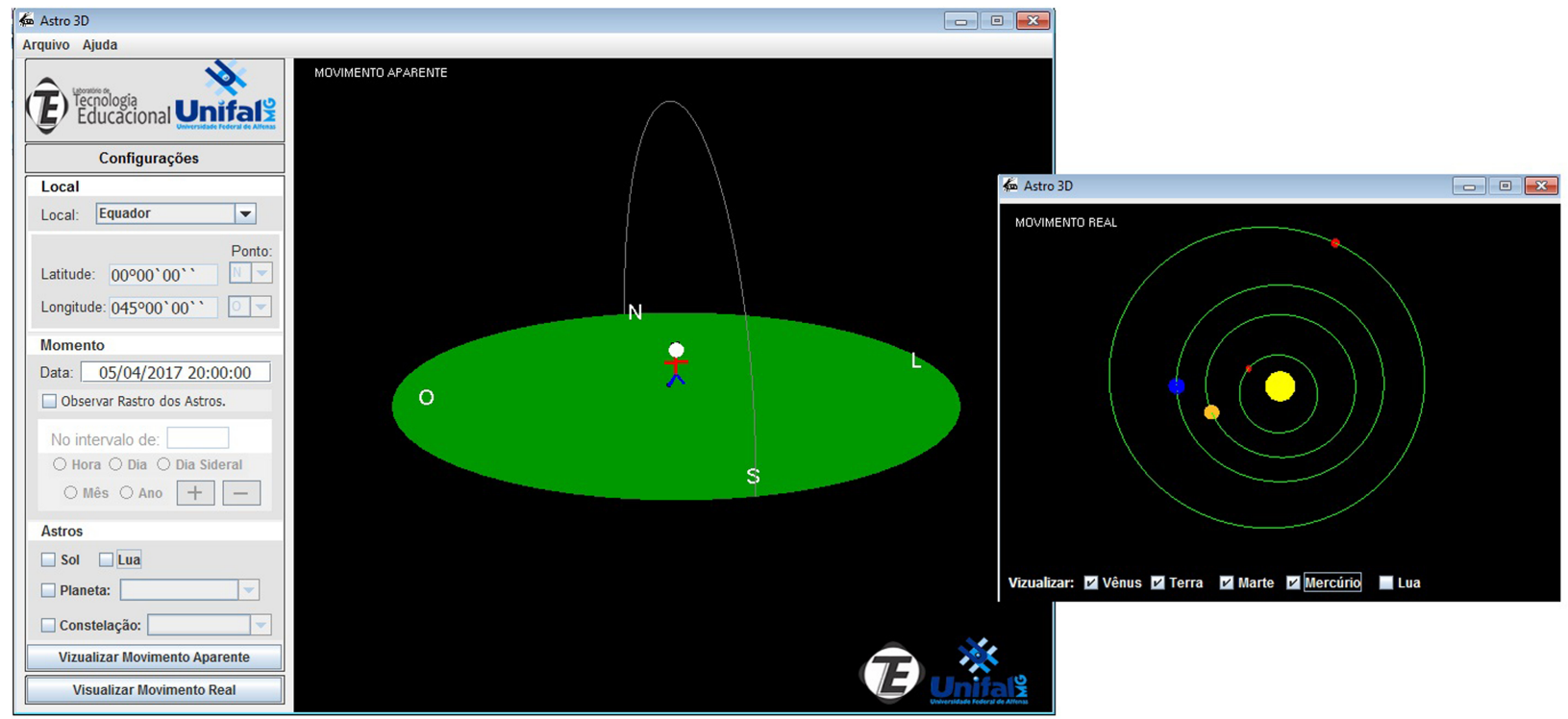

Figura 3: A figura da esquerda é a tela do Astro 3D para o movimento dos astros no referencial topocêntrico e a da lado direito no referencial heliocêntrico. 
voltados para a agricultura, o estudo do movimento do Sol tem um caráter prático. Conhecê-lo é necessário para o exercício dessas profissões.

Entretanto, apesar de estar presente nas diversas etapas da vida acadêmica a concepção que o Sol nasce sempre no ponto cardeal Leste e se põe no Oeste e a concepção de que as estações do ano ocorrem devido à variação da distância da Terra ao Sol ainda são muito comuns entre os estudantes e professores [15].

O Astro3D é uma ótima ferramenta para esclarecer essas concepções equivocadas porque com ele é possível simular o movimento aparente do Sol para qualquer local do planeta e em qualquer data e ao mesmo tempo visualizar o movimento da Terra ao redor do Sol. Essa visualização simultânea, do movimento real e do movimento aparente nos ajuda a entender que as estações do ano e a variação anual da posição do Sol ocorrem devido ao movimento de translação da Terra ao redor do Sol, e também porque a Terra faz esse movimento com seu eixo de rotação inclinado de $23,5^{\circ}$ graus em relação à vertical do plano da órbita, inclinação da eclíptica.

A Figura (4) mostra uma sequência de imagens da simulação da posição do Sol às 6 horas da manhã para as latitudes $\varphi= \pm 23,5^{\circ}$, no dia 21 dos meses de março, junho, setembro e dezembro. Ao mesmo tempo simulamos a posição da Terra ao redor do Sol nos mesmos dias, mostrando que durante esse intervalo de tempo ela realiza uma volta completa ao redor do Sol. Nas imagens é possível observar ainda que o Sol não nasce no
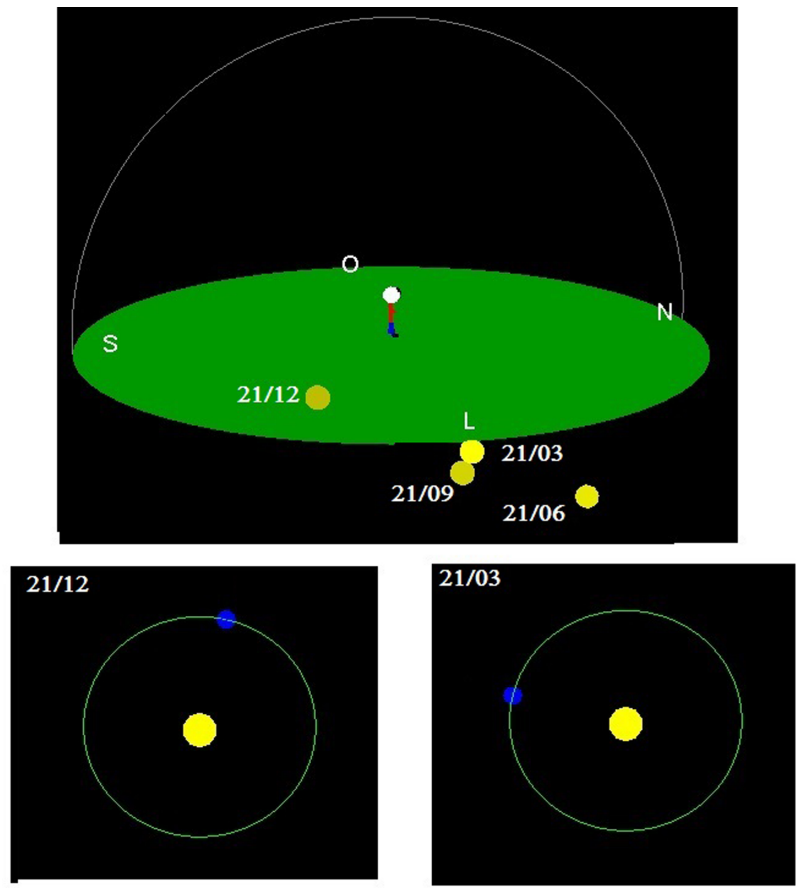

mesmo local todos os dias e que apenas no equinócio da primavera e de outono (setembro e março) ele está sobre o ponto cardeal leste. Além disso, podemos observar a diferença na posição do Sol nessas duas latitudes nos solstícios (21 de junho e 21 de dezembro).

A Figura (5) mostra a simulação da trajetória percorrida pelo Sol entre 6 horas e 18 horas para cada um dos dias 21 para as duas latitudes. Note como o tempo que o Sol permanece acima do horizonte muda ao longo do ano de forma diferente para cada uma das latitudes. Veja que com as simulações do Astro3D é possível observar a correlação entre a duração do dia claro (período que o Sol fica acima do horizonte) com a latitude do observador e a posição da Terra na sua órbita.

\subsection{Movimento dos planetas}

O estudo do movimento dos planetas é um assunto tratado tanto na disciplina de mecânica clássica quanto na de evolução das ideias da física, por exemplo quando se trata da disputa histórica entre os modelos de universo, geocêntrico e heliocêntrico, e o estudo da formulação das leis de Kepler. Nesse sentido, o Astro3D pode ser utilizado para contextualizar todos esses assuntos, uma vez que com ele é possível observar de forma simultânea o movimento aparente e o movimento real dos planetas ao redor do Sol.

Desde a antiguidade já se sabia que compreender o movimento aparente dos planetas não é uma tarefa fácil, visto que dependendo da configuração planetária (posição
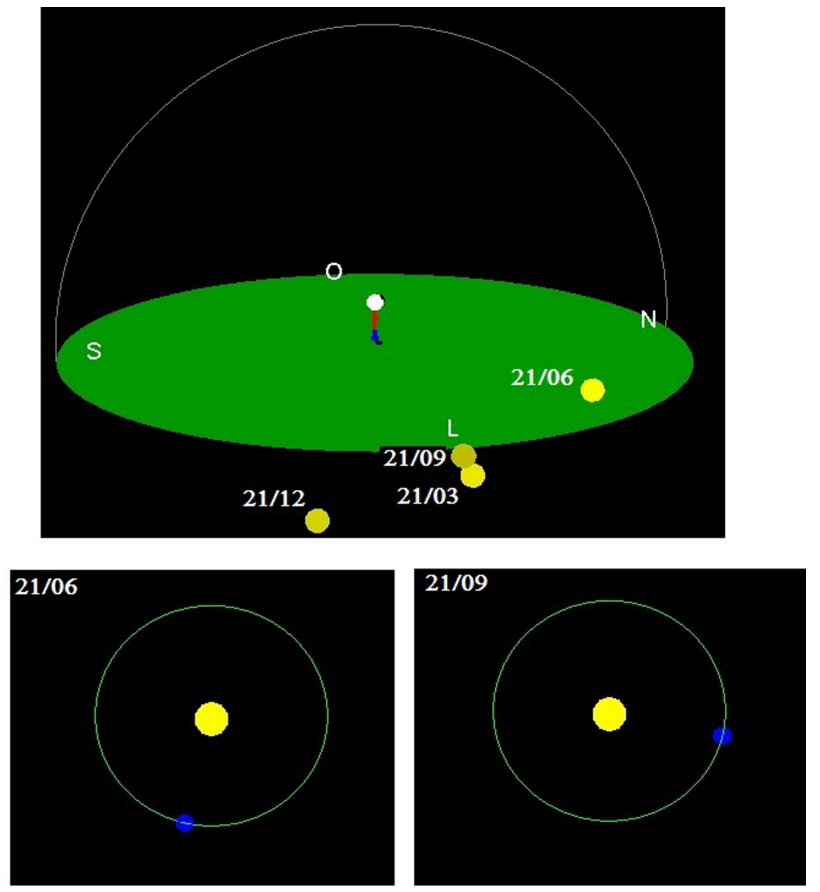

Figura 4: Tela principal do Astro3D: Simulação da posição da Sol às 06 horas da manhã em quatro datas diferentes para a latitude $23,5^{\circ}$ sul (esquerda) e $23,5^{\circ}$ norte (direita). Tela secundária do Astro3D: simulação da posição da Terra na sua órbita ao redor do Sol para cada uma das datas. 

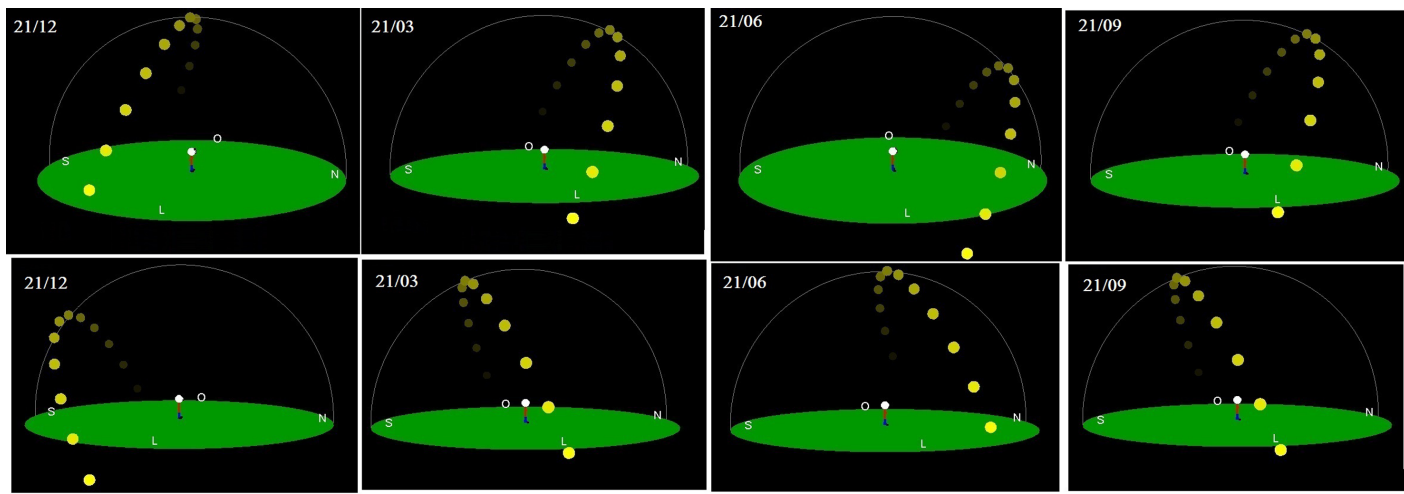

Figura 5: Simulação da trajetória aparente do Sol na esfera celeste em quatro datas diferentes para duas latitudes opostas: $23,5^{\circ}$ sul (acima) e $23,5^{\circ}$ norte (abaixo).

relativa da Terra, do Sol e do planeta) observamos o movimento direto ou o movimento retrógrado do planeta. Tanto assim que a teoria dos epiciclos surgiu da necessidade de explicar esses movimentos dentro de um modelo geométrico do universo com a Terra imóvel.

\subsubsection{O Movimento retrógrado de marte}

Um caso clássico é o movimento retrógrado de Marte (Fig.6 superior). Foi estudando os dados observacionais desse planeta, obtidos por Tycho Brahe, que Kepler chegou às suas três leis do movimento planetário [1]. Descoberta importante para a aceitação futura do modelo heliocêntrico de Copérnico como o mais adequado para descrever a configuração planetária.

A Figura (6) mostra a simulação com o Astro3D do movimento de Marte no referencial topocêntrico (movimento aparente) e no referencial heliocêntrico quando ele está se aproximando, e, posteriormente, se afastando da sua posição de oposição ao Sol (posição 3 na Fig. 6). Observem que devido à diferença de velocidade entre o movimento de translação da Terra e de Marte, aparentemente o planeta vermelho faz um movimento retrógrado. Note como o Astro3D ajuda na visualização desse fenômeno, uma vez que com ele é possível simular o movimento que demora meses para ser observado a olho
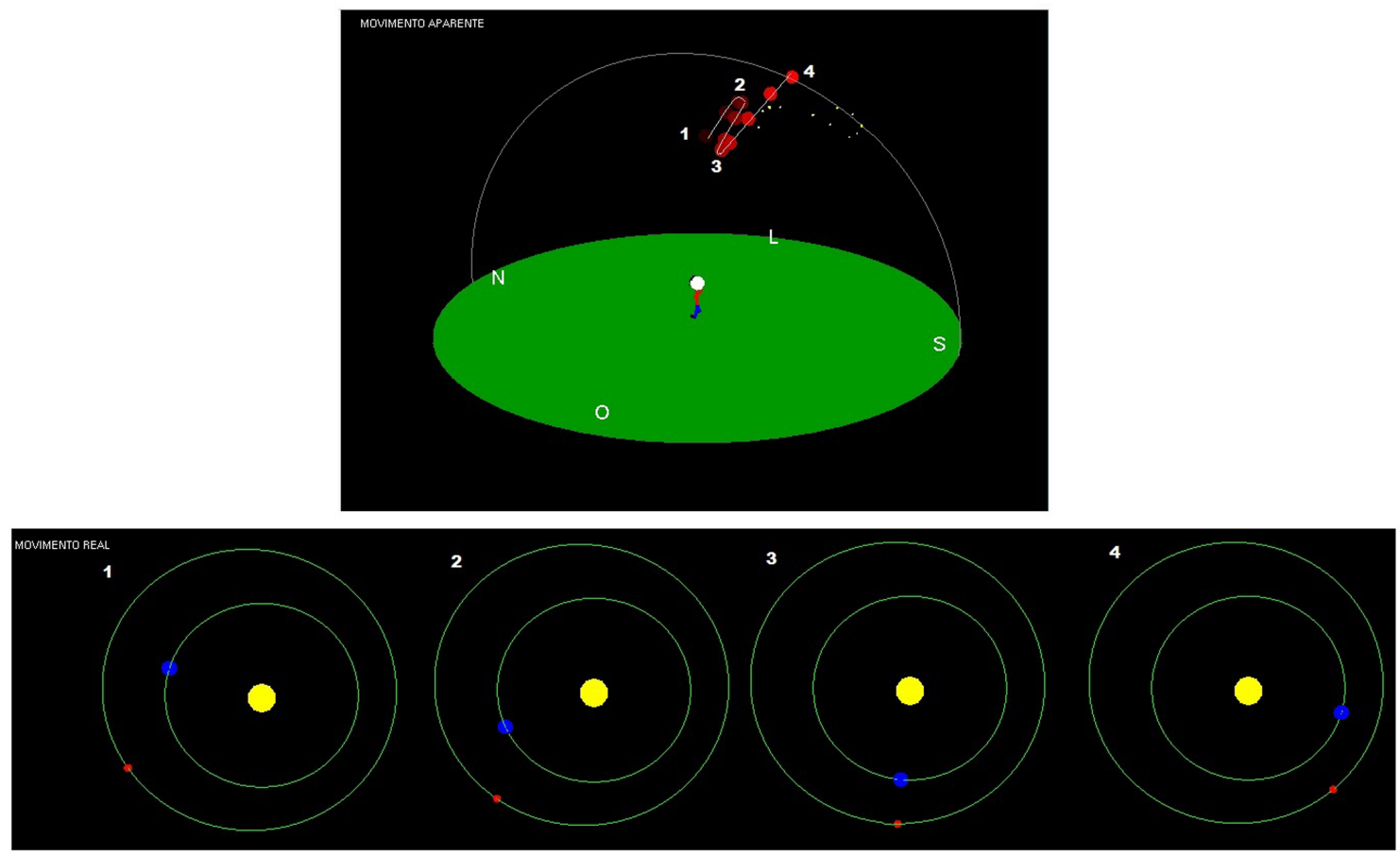

Figura 6: Simulação do movimento retrógrado de Marte. A figura de cima mostra o movimento de Marte visto por um observador na superfície da Terra (referencial topocêntrico). A figura de baixo mostra a órbita da Terra e a de Marte ao redor do Sol em quatro momentos diferentes. Essa simulação foi feita com datas entre os dias 07/04/2016 e 30/09/2016. 
nu, e ao mesmo tempo simula a configuração planetária que produz esse movimento anômalo do planeta.

Essa simulação do movimento retrógrado de Marte permite ainda a análise de como os astrônomos do passado, de uma época anterior à invenção da luneta, já sabiam diferenciar os planetas das estrelas, uma vez que a olho nu, não somos capazes de distingui-los. Isso foi possível porque com a observação sistemática, os astrônomos perceberam que, diferente das estrelas das constelações - por exemplo as do Escorpião (Fig. 6), cuja distância entre elas não se modifica com o passar do tempo - os planetas não guardam posição fixa entre as estrelas, estão sempre caminhando entre elas, são astros errantes. Isso pode ser simulado e observado com o Astro3D.

\subsubsection{Determinação da distância de planetas exteriores}

Além da simulação do movimento planetário, com o Astro3D é possível ainda calcular a distância de um planeta exterior ao Sol através do método desenvolvido por Copérnico. Nesse método, para determinar essa distância é necessário resolver o triângulo retângulo formado pelo Sol, pela Terra e pelo planeta (Fig. 7). Nessa figura vemos que:

$$
D_{P}=\frac{D_{\odot}}{\cos \beta},
$$

onde $\mathrm{D}_{\mathrm{P}}$ é a distância do planeta ao Sol, $\mathrm{D}_{\odot}$ é a distância da Terra ao Sol e $\beta$ é a distância angular entre o planeta e o Sol quando ele está em máxima elongação e pode ser calculada pela seguinte expressão:

$$
\beta=\lambda_{T}-\lambda_{P}=360^{\circ} \frac{t_{2}-t_{1}}{T_{\text {Sid Terra }}}-360^{\circ} \frac{t_{2}-t_{1}}{T_{\text {Sid Planeta }}} .
$$

Para determinar $\beta$ e calcular da distância do planeta ao Sol é necessário medir o intervalo de tempo entre duas configurações planetárias consecutivas. A primeira, $t_{1}$, é a oposição, quando o planeta está alinhado com a Terra e o Sol $\left(P_{1}-T_{1}-\mathrm{Sol}\right)$, momento mais propício para a observação, uma vez que ele está visível durante toda a noite. A segunda, $t_{2}$, é quando os segmentos que conectam o Sol à Terra e o planeta superior à Terra estão em quadratura, ou seja, formam um ângulo reto. Momento em que o planeta pode ser observado no início da noite, quando ele está em quadratura oriental, ou de madrugada, antes do nascer do Sol, quando ele está em quadratura ocidental.

Como exemplo, determinamos a distância do planeta Marte ao Sol. Primeiro observamos o planeta quando ele está em oposição e em seguida quando ele está em quadratura oriental. O intervalo de tempo medido entre uma configuração planetária e a outra foi $t_{2}-t_{1}=103$ dias. Ambas as situações simuladas com o Astro3D podem ser vistas na Figura (8). Em seguida determinamos o tempo sideral da Terra e de Marte, simulando uma translação completa para cada um dos planetas. Como o Astro3D utiliza os parâmetros orbitais dos planetas para realizar essas simulações os valores encontrados para $T_{\text {Sid Terra }}=365,24$ dias e $T_{\text {Sid Planeta }}=687$ dias são praticamente os mesmos atualmente aceitos para esses planetas. Assim, da Equação (8) temos que $\beta=47,55^{\circ}$ e da Equação (7) $D_{\text {Marte }}=1,48 D_{\odot}$. Valor consistente com a distância média desse planeta ao Sol [1].

\section{Considerações Finais}

Nesse artigo nós apresentamos o Astro3D e mostramos três exemplos que ilustram como ele pode ser utilizado no ensino de Astronomia e de Física. Aos leitores interessados em mais exemplos nós recomendamos a dissertação de mestrado, aprovada no programa do Mestrado Na-

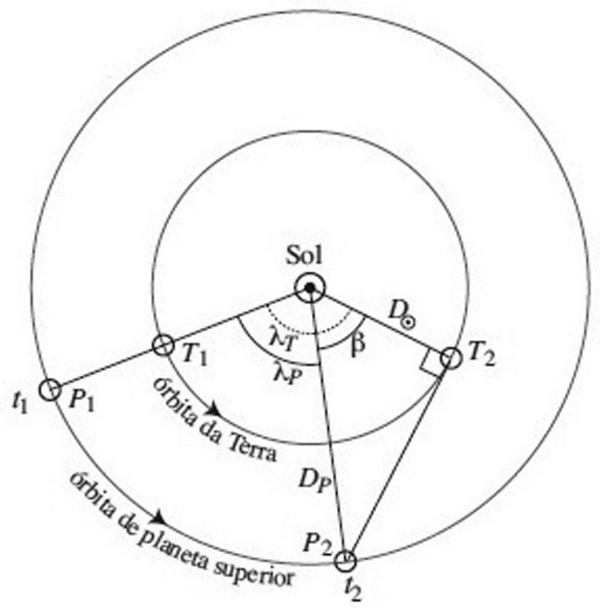

Figura 7: Configurações planetárias. $\mathrm{P}_{1}$ e $\mathrm{P}_{2}$ são as posições do planeta exterior quando ele está em oposição $\left(\mathrm{t}_{1}\right)$ e em quadratura $\left(t_{2}\right)$. $T_{1}$ e $T_{2}$ são as posições da Terra na sua órbita nos instantes $t_{1}$ e $t_{2} . \lambda_{T}, \lambda_{P}$ e $\beta$ são distâncias angulares. $D_{P}$ e $D_{\odot}$ são as distâncias dos planetas ao Sol. Figura extraída da referência [9]. 

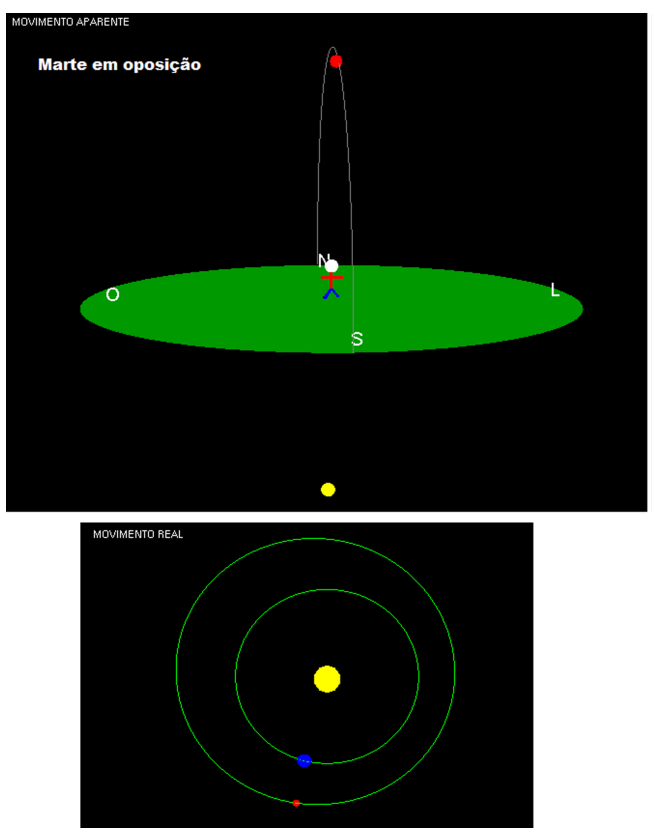
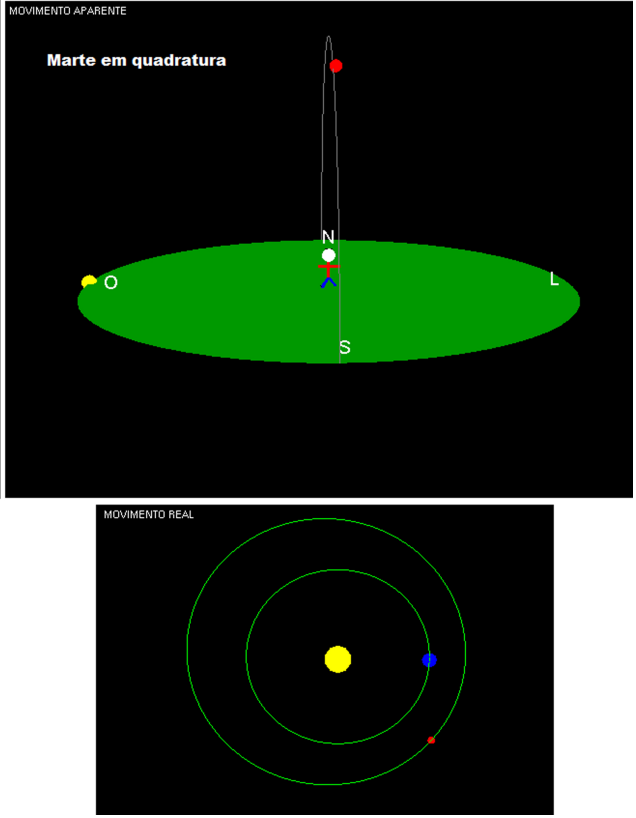

Figura 8: Simulação do momento em que Marte está em oposição ao Sol e quando ele está em quadratura. Abaixo a posição do planeta na sua órbita para cada uma das configurações planetárias, oposição e quadratura. As datas da simulação são: oposição, $21 / 05 / 2016$ às 0 horas e a quadratura, 01/09/2016 às 18 horas.

cional Profissional de Ensino de Física, que pode ser consultada na referência [16].

No momento estamos desenvolvendo a versão do Astro3D para dispositivos móveis [17] e estamos trabalhando também no aperfeiçoamento de algumas funcionalidades e incluindo outras. Essa primeira versão do Astro3D, que roda no sistema operacional Windows, está disponível no endereço eletrônico das referências [18] e [19] e em breve as outras versões poderão ser baixadas no mesmo local.

\section{Agradecimentos}

Os autores agradecem ao valioso parecer do árbitro, que contribuiu para o aprimoramento deste trabalho, à CAPES e a FAPEMIG pelo apoio financeiro.

\section{Referências}

[1] Antônio S.T. Pires, Evolução das Ideias da Física (Editora Livraria da Física, São Paulo, 2011).

[2] Moysés H. Nussenzveig, Curso de Física Básica: Mecânica (Edgard Blucher, São Paulo, 2013).

[3] B.F. Rizzuti e J.S. Silva, Revista Brasileira de Ensino de Física 38, e3302 (2016).

[4] A. Justiniano e R. Botelho, Revista Brasileira de Ensino de Física 38, e4311 (2016).

[5] C. Fiolhais e J. Trindade, Revista Brasileira de Ensino de Física 25, 259 (2003).

[6] Brasil, PCN + Ensino Médio: Orientações Educacionais Complementares aos Parâmetros Curriculares Nacionais: Ciências da Natureza, Matemática e suas Tecnologias (MEC-SEMTEC, Brasília, 2002).
[7] L.D.D. Menezes, Tecnologia no Ensino de Astronomia na Educação Básica: Análise de Recursos Computacionais na ação Docente. Dissertação de Mestrado. Universidade Federal de Uberlândia, 2011.

[8] J.L Lawrence, Basic Astronomy with a PC (WillmannBell, Richmond, 1989).

[9] G.L.N. Bierrenbach, Astronomia de Posição, disponível em http://www.astro.iag.usp.br/gastao/ astroposicao.html, acessado em 20/03/2017.

[10] H. Goldstein, Classical Mechanics (Addison-Wesley, Reading, 1980).

[11] K.R. Symon, Mecânica (Editora Campus, Rio de Janeiro , 1996).

[12] R. Fitzpatrick, An Introduction to Celestial Mechanics (The University of Texas at Austin, Austin, 2011).

[13] A. Gilat, V. Subramaniam, Métodos Numéricos para Engenheiros e Cientistas (Bookman, Porto Alegre, 2008).

[14] OpenGL, https://www.opengl.org/ acessado em 20/03/2017.

[15] P. Bedaque e P.S. Bretones, Revista Brasileira de Ensino de Física 38, e3307 (2016).

[16] L. Moraes, Uma Proposta de Sequência Didática para o Ensino de Astronomia na Educação Básica com o Software Astro3D. Dissertação de Mestrado, Departamento de Física, Universidade Federal de Alfenas, 2016.

[17] A.B. Gonçalves, E.M. Silva, R.B. Botelho, A. Justiniano e P.A. Bressan, in: XXII Simpósio Nacional de Ensino de Física - SNEF, São Carlos, p. 1-8 (2017).

[18] Astro3D, http://www.unifal-mg.edu.br/mnpef/node/ 20, acessado em 20/03/2017.

[19] Astro3D, http://www.bcc.unifal-mg.edu.br/lte/ acessado em 20/03/2017. 